\title{
ON THE KINETICS OF OXIDATION OF AUSTENITIC STAINLESS STEELS AISI 304 AND INCOLOY 800H
}

\author{
J.C. LANGEVOORT *, L.J. HANEKAMP ** and P.J. GELLINGS *** \\ Twente University of Technology, P.O. Box 217, 7500 AE Enschede, The Netherlands
}

Received 12 May 1986; accepted for publication 20 February 1987

\begin{abstract}
The interaction of oxygen with clean surfaces of stainless steels has been studied by spectroscopic ellipsometry and AES. The reaction involves chemisorption and dissolution of oxygen into the surface of the metal via a place-exchange mechanism. Oxide thickening occurs via cation and anion migration under the influence of an electric field. The activation energy increases with increasing oxide thickness and the final activation energy equals the energy needed to break the bonds between oxygen and metal ions in the oxide, suggesting diffusion via lattice sites.
\end{abstract}

\section{Introduction}

It has been shown that the oxidation of metals and alloys is strongly influenced by cold work [1-5], indicating that the surface conditions play an important role in the oxidation mechanism. The interaction of oxygen with atomically clean metal surfaces can generally be described by dissociative chemisorption, followed by oxide nucleation and lateral growth, and subsequently oxide thickening.

The chemisorbed layer may be reconstructed or non-reconstructed and the concentration at which the oxide nucleates may vary. The kinetics of chemisorption often shows a Langmuir behaviour. In the case of $\mathrm{Ni}(111)$ and $\mathrm{Ni}(100)$, Holloway and Hudson [6,7] report a steep decrease of the sticking coefficient with coverage. At the onset of nucleation it rises slightly, but after a maximum it falls again. The exposure required to complete the $c(2 \times 2)$ structure on a $\mathrm{Ni}(100)$ varies from $15 \mathrm{~L}$ [8] to about $50 \mathrm{~L}$ [9]. Hanekamp and van Silfhout [10] have shown that the initial oxidation behaviour of the $\mathrm{Ni}(110)$ surface is influenced by the annealing treatment given prior to the oxidation experiment. They report that the same change in ellipsometric

* Present address: Nederlandse Philipsbedrijven Licht, Postbus 218, 5600 MD Eindhoven, The Netherlands.

** Department of Applied Physics.

*** Department of Chemical Technology.

0169-4332/87/\$03.50 $\odot$ Elsevier Science Publishers B.V.

(North-Holland Physics Publishing Division) 
parameter $\Delta$ may correspond to different oxygen concentrations in the layer on top of the metal surface indicating that the annealing temperature affects the polarizability of the oxygen. Their oxidation curves for $\mathrm{Ni}(110)$ after annealing at $570 \mathrm{~K}$ look very much like those reported by Holloway [11]. However, the saturation at $0.25 \mathrm{ML}$, as reported by Holloway [11] is absent for the oxidation after annealing at $740 \mathrm{~K}$.

As soon as a continuous layer has been formed, the diffusion of cations, anions or electrons through the oxide can become the rate-limiting step. Models concerning oxide film formation have been reviewed by Lawless [13] and only a few models are discussed briefly here. Mott [14] described the subsequent oxidation by the assumption that metal ions diffuse through the oxide film, by an outward diffusion of interstitials or an inward movement of cation vacancies, and react with the oxygen at the oxide/gas interface. It has been suggested that due to a quantum mechanical tunneling effect electrons can move through a 3.0 to $4.0 \mathrm{~nm}$ thick oxide layer. For a film with a thickness smaller than $2.0 \mathrm{~nm}$ it is assumed that ion movement through the film is the rate-limiting step and thus a parabolic equation describes the kinetics. Between 3.0 and $4.0 \mathrm{~nm}$, electron tunneling was regarded to control the oxidation. The rate of oxide growth is then given by:

$\mathrm{d} x / \mathrm{d} t=C \exp [(-4 \pi x / h) \sqrt{2 m V}]$,

where $x$ is the oxide thickness, $V$ the potential difference, $m$ the mass, $C=10^{7} \mathrm{~cm} / \mathrm{s}, t$ is time, and $h$ Planck's constant. Integration yields the logarithmic equation:

$x=A \ln (B t+1)$,

where $A$ and $B$ are constants.

For films exceeding $5.0 \mathrm{~nm}$ either thermionic emission or diffusion of electrons was assumed to be the rate-limiting step, since the tunneling effect can no longer be effective. Diffusion gives a parabolic behaviour, while the thermionic emission leads to inverse logarithmic kinetics.

Cabrera and Mott [15] put forward a theory of low temperature oxidation, based on the assumption that migration of anions occurs under the influence of a potential across the growing oxide. This field, due to the ionization of both oxygen at the gas/oxide interface and metal at the oxide/metal interface, assists metal ions to cross the thin layer without an appreciable contribution from the thermal movement and leads to an inverse logarithmic law:

$1 / x=A-B \ln t$

where $A$ and $B$ are constants.

The essential feature of this model is that the activation energy for the movement of a cation is so large that the jump frequency is negligible unless $\frac{1}{2} q a F \gg k T$, so that the activation energy is lowered appreciably ( $q$ is the charge of the ion, $a$ is the jump distance and $F$ the field across the oxide). 
Eley and Wilkinson [16] supposed that the activation energy is of the form $W_{\mathrm{A}}=W_{0}+\mu x$ where $\mu$ is a constant depending on the film structure. This leads to a direct logarithmic equation:

$x=A \ln (1+B t)$.

The model of Cabrera and Mott [15] has one strong limitation because only cation migration is taken into account, while some oxides are reported to grow via anion migration (e.g., aluminium [17]).

Fehlner and Mott [18] discussed the low temperature oxidation following the assumptions of Cabrera and Mott, however, they proposed a model with anion as well as cation migration. They replaced the assumption of a constant potential by that of a constant field. In this way, they assumed that the partially incorporated oxygen ions at the oxide/gas surface must cross an activation barrier, which is decreased by the presence of an electric field. If the field strength is constant across the oxide, then the activation energy for ionic transport increases with increasing oxide thickness. However, as the oxide thickens reconstruction and recrystallization may occur. In order to take this into account, the structural term $\mu x$, proposed by Eley and Wilkinson [16], is introduced, resulting in the rate equation:

$\mathrm{d} x / \mathrm{d} t=C \exp \left[-\left(W+\mu x-\frac{1}{2} q a F\right) / k T\right]$.

In the present investigation an automatic spectroscopic ellipsometer has been used in order to obtain information about successive stages of the low temperature oxidation of stainless steel AISI 304 and Incoloy $800 \mathrm{H}$.

\section{Experimental}

The experiments were performed in an UHV system, which was provided with facilities for spectroscopic ellipsometry (400-800 nm), AES (3 keV primary beam, sample current 3-10 $\mu \mathrm{A} / \mathrm{cm}^{2}$ ), ion bombardment and a quadrupole mass analyser for residual-gas analysis.

The ellipsometric experiments were performed at an angle of incidence of $66.00^{\circ} \pm 0.05^{\circ}$. Oxidations were performed with pure oxygen $(99.995 \%)$ at pressures between $10^{-4}$ and $10^{-6} \mathrm{~Pa}$ and at temperatures between 300 and $720 \mathrm{~K}$. The experimental procedures are described in ref. [1] and the ellipsometer, which was of a PSA ${ }_{\text {rot }}$ A configuration, is essentially described in ref. [19]. The chemical compositions of the stainless steels, used in these investigations, are given in table 1 . The materials were polycrystalline and fully annealed before applying cold work.

Cleaning of the sample in the UHV system was performed with Ar ion bombardment $\left(600 \mathrm{eV}\right.$ primary beam, sample current $\sim 0.7 \mu \mathrm{A} / \mathrm{cm}^{2}, 70^{\circ}$ off-normal). The samples were not annealed after sputtering. All processes 
Table 1

Chemical compositions (wt\%) of the stainless steels

\begin{tabular}{lllllllll}
\hline & $\mathrm{Cr}$ & $\mathrm{Ni}$ & $\mathrm{Mn}$ & $\mathrm{Si}$ & $\mathrm{Ii}$ & $\mathrm{S}$ & $\mathrm{C}$ & $\mathrm{Fe}$ \\
\hline AISI 304 & 17.39 & 8.88 & 1.27 & 0.70 & - & 0.01 & 0.044 & Balance \\
Incoloy $800 \mathrm{H}$ & 19.90 & 31.70 & 0.72 & 0.49 & 0.42 & 0.08 & 0.080 & Balance \\
\hline
\end{tabular}

were followed by monitoring the changes in the ellipsometric parameters $\Delta$ and $\psi: \delta \Delta$ and $\delta \psi$ are defined by $\delta \Delta=\bar{\Delta}-\Delta$ and $\delta \psi=\bar{\psi}-\psi$, where $\bar{\Delta}, \bar{\psi}$ refer to the clean and $\Delta, \psi$ to the oxidized surface. Most of the experiments have been performed at a wavelength of $632.8 \mathrm{~nm}$, however $500.0 \mathrm{~nm}$ has also been used.

\section{Results}

\subsection{Incoloy $800 \mathrm{H}$}

The oxidation experiments at room temperature were performed at four different pressures. At low pressures $\left(P_{\mathrm{O}_{2}} \leq 4.0 \times 10^{-6} \mathrm{~Pa}\right)$ the oxidation curve shows a sigmoidal shape, while at pressures $\geq 2.3 \times 10^{-5} \mathrm{~Pa}$ the ellipsometric parameters $\delta \Delta$ and $\delta \psi$ increase very fast until they reach a value after which subsequent oxidation is very slow (fig. 1).

The low temperature oxidation (LTO) is governed by an incoming oxygen flux at the surface. The probability for an oxygen atom to hit the uncovered surface is given by $1-A / A_{\text {tot }}$, where $A$ and $A_{\text {tot }}$ represent the covered and total area of the surface respectively. The increase in the area covered by oxygen is given by:

$\mathrm{d} A=\left(1-A / A_{\text {tot }}\right) s a_{\mathrm{O}} \phi \mathrm{d} t$,

where $s, a_{\mathrm{O}}$ and $\phi$ are the sticking coefficient of an oxygen atom on the basal plane, the area occupied by a single oxygen atom and the incoming flux of oxygen atoms. Integration yields:

$1-\theta=1-A / A_{\text {tot }}=\exp \left(-s a_{\mathrm{O}} \phi t\right)$.

If one assumes $\theta=\delta \Delta / \delta \Delta_{\mathrm{fc}}$, where $\delta \Delta_{\mathrm{fc}}$ is the $\delta \Delta$ corresponding to a fully covered surface, eq. (7) gives the dependence of the change in the ellipsometric parameter $\Delta$ with time. The drawn lines in figs. 1 and 2 are the calculated values for the LTO using expression (7) (the vertical bars represent the experimental data). If one assumes dissociative chemisorption to be the first step in the oxidation process, $a_{0}$ becomes the $\mathrm{O}^{2-}$ area, which is $4.5 \times 10^{-20}$ $\mathrm{m}^{2}$. Together with $\delta \Delta_{\mathrm{fc}}=1.8^{\circ}$, the sticking coefficient becomes 0.042 . If the process is a physisorption process, the area of atomic oxygen should be used, giving a sticking coefficient of 0.05 . 


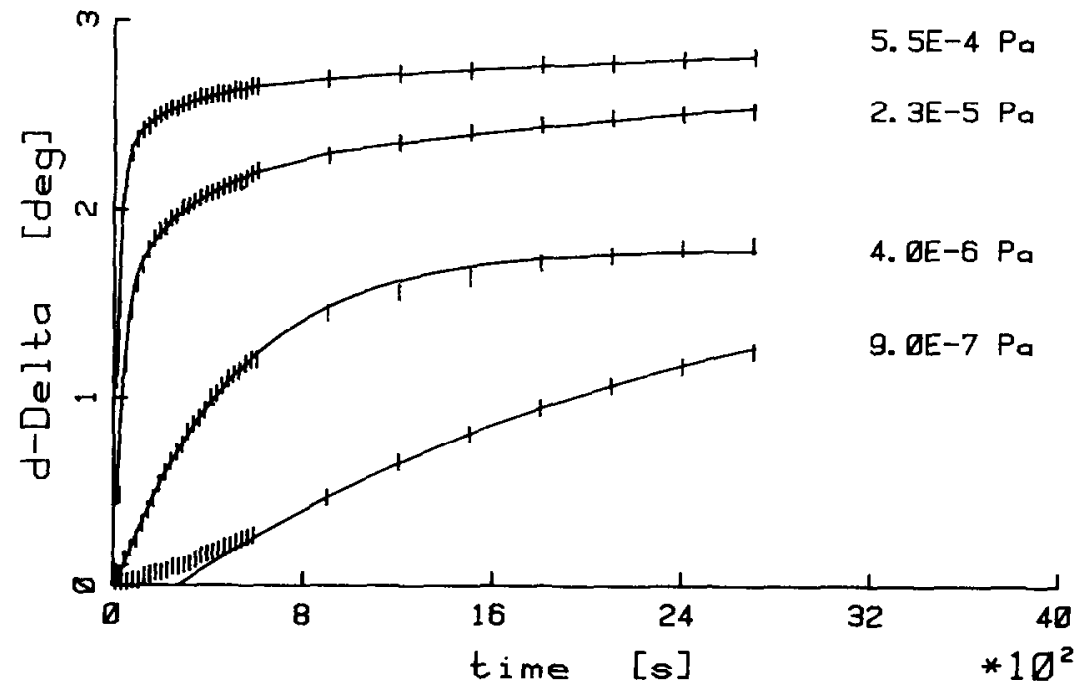

Fig. 1. Ellipsometric parameter $\Delta$ as a function of exposure to oxygen for different oxygen pressures (Incoloy $800 \mathrm{H}$, rolled) at $300 \mathrm{~K}$.

The $\delta \Delta$, due to a fully covered surface $\left(\sim 1.8^{\circ}\right)$, corresponds to an oxide thickness of approximately $0.9 \mathrm{~nm}$ (taking the proportionally constant $\zeta=2.0$ $\mathrm{deg} / \mathrm{nm}$ [27]), which is about 3 monolayers of oxygen. This value is in good

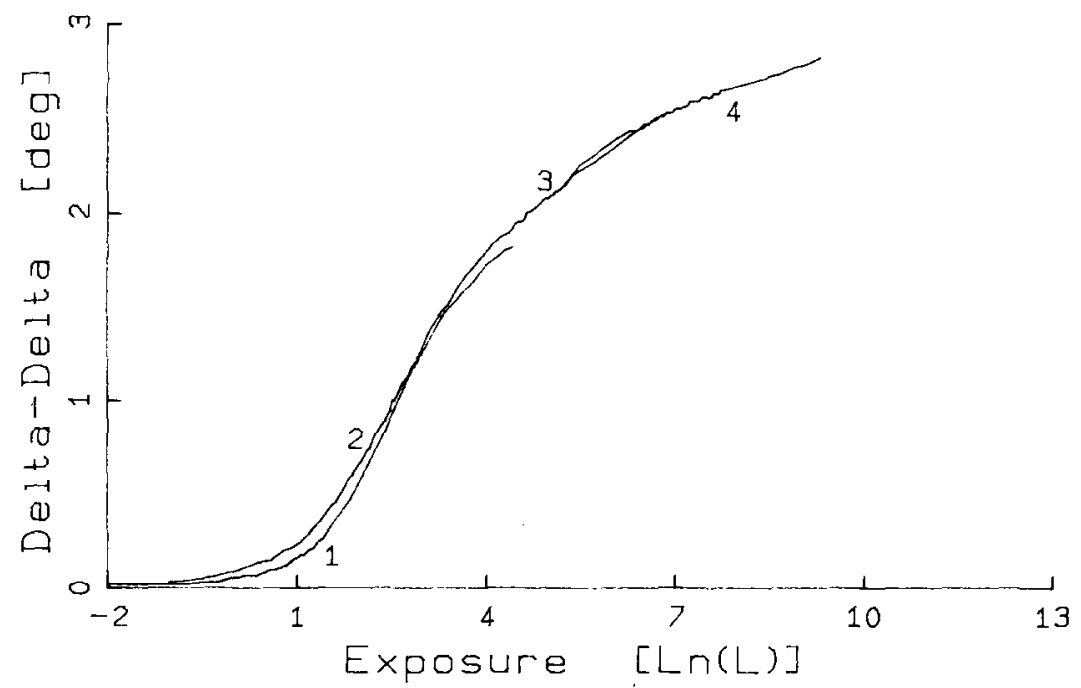

Fig. 2. Ellipsometric parameter $\Delta$ as a function of the natural logarithm of the exposure to oxygen for different oxygen pressures (Incoloy $800 \mathrm{H}$, rolled): (1) $9.0 \times 10^{-7} \mathrm{~Pa}$, (2) $4.0 \times 10^{-6} \mathrm{~Pa}$, (3) $2.5 \times 10^{-5} \mathrm{~Pa}$, (4) $3.5 \times 10^{-4} \mathrm{~Pa}$ all at $300 \mathrm{~K}$. 


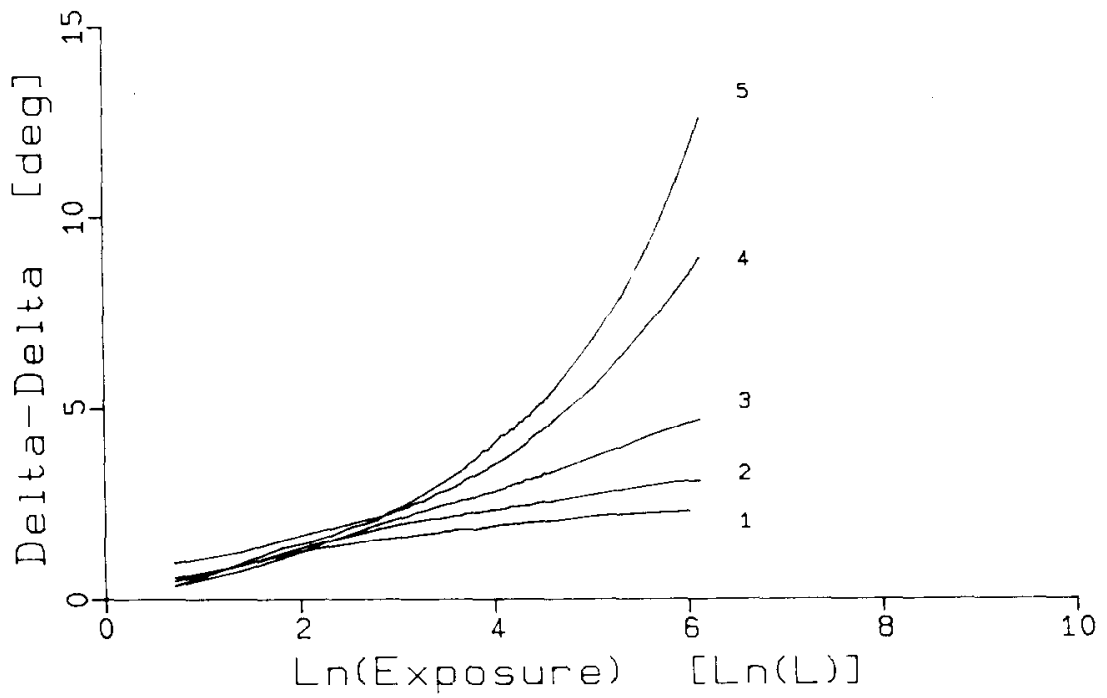

Fig. 3. Ellipsometric parameter $\Delta$ as a function of exposure to oxygen at different temperatures and constant pressure $P_{\mathrm{O}_{2}}=2.3 \times 10^{-5} \mathrm{~Pa}$ : (1) $300 \mathrm{~K}$, (2) $375 \mathrm{~K}$, (3) $480 \mathrm{~K}$, (4) $570 \mathrm{~K}$, (5) 720 K. (Incoloy, $800 \mathrm{H}$, undeformed.)

agreement with the values reported for $\mathrm{Ni}(100), \mathrm{Ni}(110)$ and $\mathrm{Ni}(111)$ surfaces [20].

Fig. 2 shows that the oxidation mechanism is independent of the product of oxygen pressure and time.

The temperature dependence of $\delta \Delta$ as a function of exposure to oxygen is shown in fig. 3. All curves are taken at an oxygen pressure of $2.3 \times 10^{-5} \mathrm{~Pa}$.

The initial oxidation seems to be independent of the temperature, but after reaching a critical oxide thickness, the influence of the temperature becomes noticeable. The critical thickness of about $0.9 \mathrm{~nm}\left(\delta \Delta=1.8^{\circ}\right)$, is the same as the thickness of a fully covered surface! The subsequent LTO can be described by a logarithmic equation and at high temperatures $(T \geq 470 \mathrm{~K})$ it can be described by a parabolic one.

\subsection{AISI 304}

The LTO of AISI 304 does not show the same behaviour as that of Incoloy $800 \mathrm{H}$ : even at low pressures the oxidation of AISI 304 starts immediately. The mechanism of oxidation is independent of pressure on a Langmuir scale (fig. 4). Fig. 5 shows the temperature dependence of the oxidation of AISI 304 $\left(P_{\mathrm{O}_{2}}=2.3 \times 10^{-5} \mathrm{~Pa}\right)$. Like Incoloy $800 \mathrm{H}$, it shows a temperature independent part up to $\delta \Delta=2.1^{\circ}$, which corresponds to an oxide thickness of $1.0 \mathrm{~nm}$. 


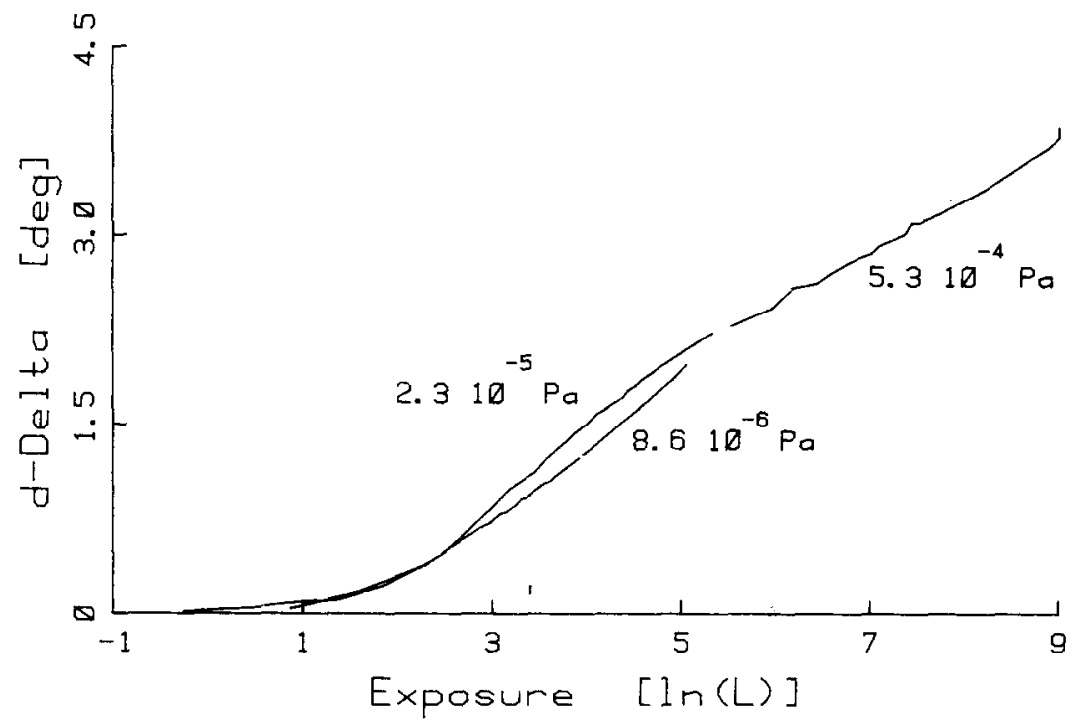

Fig. 4. Ellipsometric parameter $\Delta$ as a function of exposure to oxygen at constant temperature, $T=300 \mathrm{~K}$, and different pressures. (AISI 304 undeformed.)

The subsequent oxidation of AISI 304 can be described by a logarithmic equation at low temperatures, and the high temperature oxidation by a parabolic one.

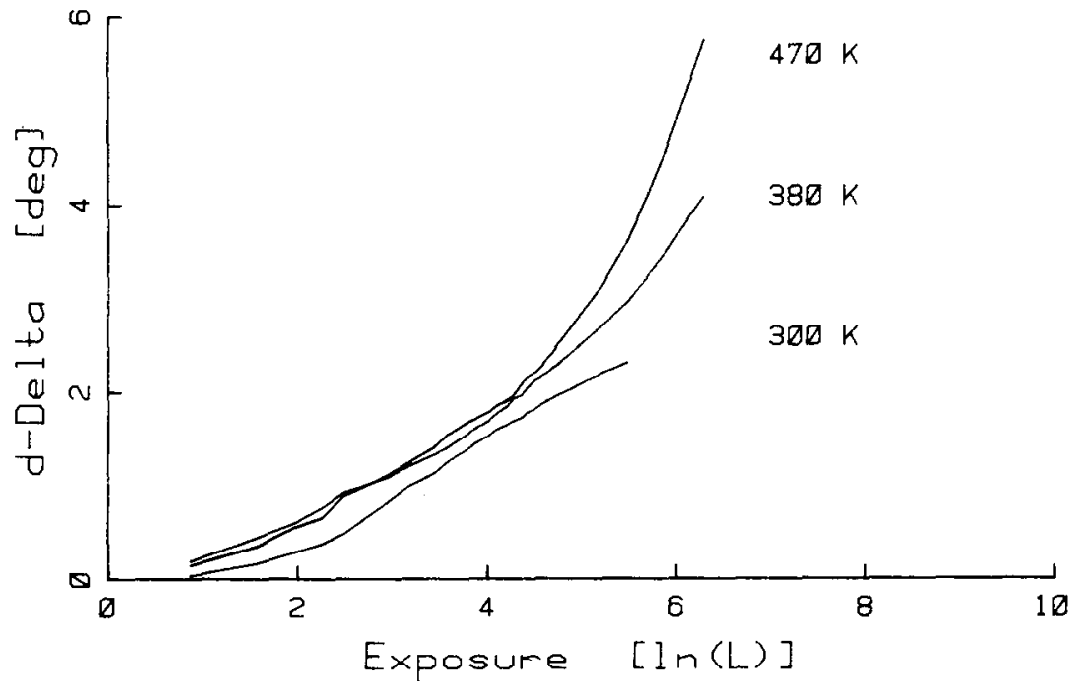

Fig. 5. Ellipsometric parameter $\Delta$ as a function of exposure to oxygen at constant pressure $\left(P_{\mathrm{O}_{2}}=2.3 \times 10^{-5} \mathrm{~Pa}\right)$ and different temperatures. (AISI 304, undeformed.) 


\subsection{Influence of cold work}

The oxidation of AISI 304 is affected considerably by cold deformation. Due to cold work a phase transformation occurs in which some martensite formation takes place in the austenitic grains. The grain boundaries between the austenite and martensite grains show a very high diffusivity for $\mathrm{Cr}$ and $\mathrm{Fe}$ [21], explaining the increase of the oxidation resistance of AISI 304 as a result of cold work $[1,2,22]$.

Although Ar ion bombardment is used in all our investigations, this does not seem to influence the oxidation behaviour of AISI 304, the oxidation resistance still increases with increasing cold work. For Incoloy $800 \mathrm{H} \mathrm{a}$ decrease in oxidation resistance with increasing cold work has been reported [22]. However, this influence has not been seen in this study - probably due to an increased number of defects created by the bombardment procedure.

It made no difference whether the steel was pretreated and no influence of cold work on the oxidation resistance was observed, so that it is concluded that the surface layer has been amorphized by the argon bombardment.

All samples showed a relaxation effect after ion bombardment was stopped, i.e. the ellipsometric parameters $\Delta$ and $\psi$ showed a small decrease. This was of the same order of magnitude $\left(\delta \Delta=0.2^{\circ}, \delta \psi=0.02^{\circ}\right)$, and had a similar relaxation time ( $t \simeq 45 \mathrm{~min}$ ) as reported for $\mathrm{Ni}(110)$ [23]. This decrease in $\Delta$ and $\psi$ is caused by the segregation of oxygen towards the surface. It is highly unlikely that this oxygen is coming from the residual gas as the background pressure was less than $10^{-8} \mathrm{~Pa}$, with $\mathrm{CO}$ and $\mathrm{CO}_{2}$ as its main constituents and oxygen itself was never detected.

\subsection{Composition of oxide layers}

Oxide compositions were determined using successive Ar ion bombardment and AES cycles. The depth profiles of the oxides formed on AISI 304 and Incoloy $800 \mathrm{H}$ were observed to be almost the same, i.e., an inner layer rich in chromium and an outer layer rich in iron. The depth profile of the composition did not depend on pretreatment. An AES sputter profile of undeformed Incoloy $800 \mathrm{H}$ is given in fig. 6 . The concentrations were calculated using $[X]=\alpha_{\mathrm{i}} h_{\mathrm{i}} / \sum \boldsymbol{\alpha}_{\mathrm{i}} h_{\mathrm{i}}$,

where $\alpha_{\mathrm{i}}$ are correction factors $(\mathrm{C}(273): 5.0, \mathrm{O}(515): 2.0, \mathrm{Cr}(528): 3.3, \mathrm{Fe}(651)$ : 5.0, $\mathrm{Ni}(848): 3.6)$ ) and $h_{\mathrm{i}}$ is the peak-to-peak height of element $\mathrm{i}$. In fig. $6 \mathrm{a}$ oxygen is included in the calculation but in fig. $6 \mathrm{~b}$ it is not. In the latter representation it is more clear where enrichment of a metal occurs.

The ion-dose instead of oxide thickness is given along the $x$-axis, because there is a large uncertainty in the relation between the two. There are several 

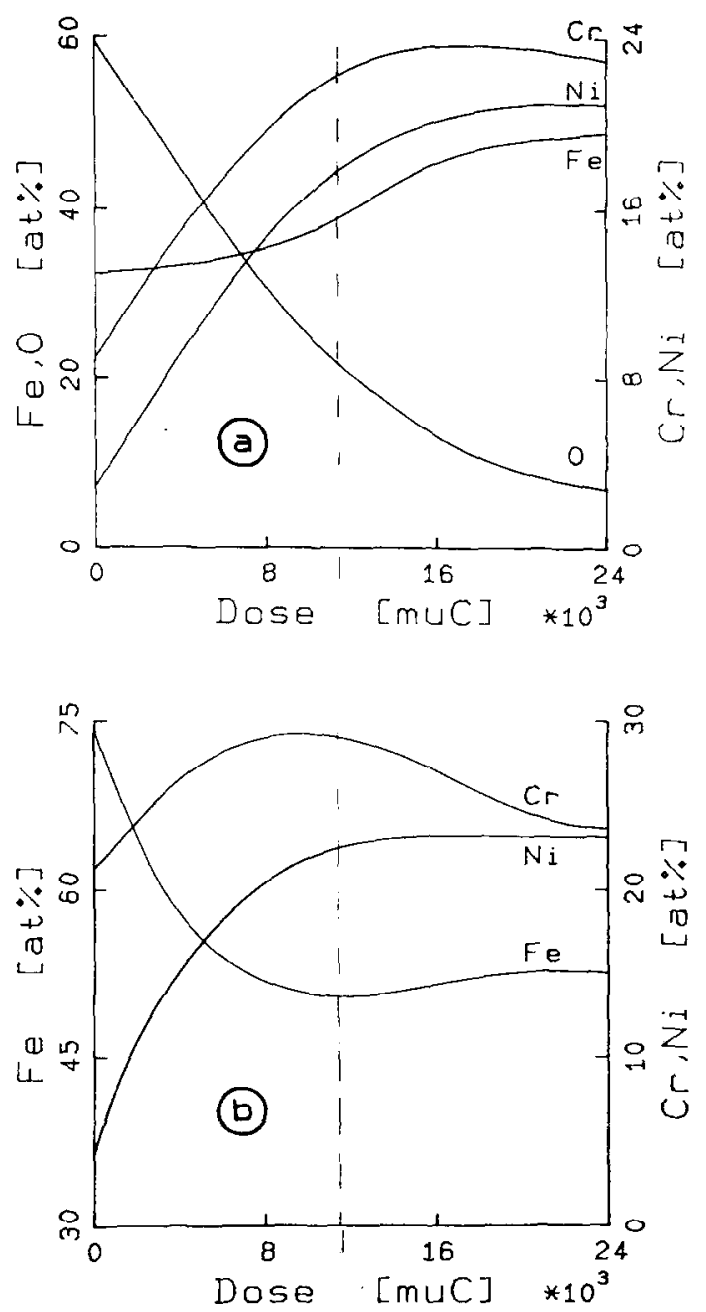

Fig. 6. AES sputter profile of undeformed Incoloy $800 \mathrm{H}$ after exposure to oxygen $\left(P_{\mathrm{O}_{2}}=2.3 \times 10^{-5}\right.$ $\mathrm{Pa}, T=300 \mathrm{~K})$ : (a) $\left[x_{\mathrm{i}}\right]=\alpha_{\mathrm{i}} h_{\mathrm{i}} /([\mathrm{O}]+[\mathrm{Fe}]+[\mathrm{Cr}]+[\mathrm{Ni}])$; (b) $\left[x_{\mathrm{i}}\right]=\alpha_{\mathrm{i}} h_{\mathrm{i}} /([\mathrm{Fe}]+[\mathrm{Cr}]+[\mathrm{Ni}])$.

reasons why the ion dose is not uniquely related to the thickness of the sputtercd layer:

(1) $\mathrm{Fe}^{3+}$ is reduced to $\mathrm{Fe}^{2+}[24]$;

(2) preferential sputtering of one of the components may occur;

(3) the sputter rate may change gradually from the oxide to the bulk value, whenever the bulk is internally oxidized.

The total oxide thickness of fig. 6 can be estimated using the ellipsometric 
data to be about $3.0 \mathrm{~nm}$. The dashed line in fig. 6 gives the presumed oxide/metal interface.

From XPS data it has been shown that $\mathrm{Ni}$ is not involved in the oxidation process and is not oxidized [24]. From this it is concluded that the oxide/metal interface is situated where the $\mathrm{Ni}$ reaches its bulk concentration. This procedure differs somewhat from that suggested by Seo and Sato [25], in which they assume that the oxide/metal interface is situated at the point where the oxygen concentration reaches the bulk value.

This method does not take internal oxidation into account and it assumes that the oxide stoichiometry may vary from 60 at $\%$ to 0 at $\%$ oxygen, which is very unlikely.

It is concluded that some chromium is internally oxidized at grain boundaries. Confirmation for this is obtained from the Auger sputter profiles, which show an enrichment in chromium of the surface layer just below the oxide/metal interface.

\section{Discussion}

Based on the following observations

(1) the temperature independence of the initial oxidation;

(2) the linear dependence of $\delta \Delta$ and $\delta \psi$ up to $\delta \Delta \approx 1.8^{\circ}(\sim 3 \mathrm{ML})$;

(3) the dependence of $\delta \Delta$ on oxygen concentration in the surface layer;

(4) the simultaneous oxidation of iron and chromium [24];

(5) the dependence of the initial oxidation on the argon bombardment conditions;

it is concluded that the initial oxidation behaviour of Incoloy $800 \mathrm{H}$ and AISI 304 is governed by the dissolution of oxygen in the metal surface up to a saturation corresponding to a $3 \mathrm{ML}$ coverage. A $3 \mathrm{ML}$ coverage has also been reported for $\mathrm{Ni}(110)$ [23] and $\mathrm{Ni}(100)$ [6,7]. Mitchel et al. [8] reported that the oxidation is strongly influenced by the amount of carbon present at the surface prior to oxidation. By changing the carbon fraction from 0.1 to 0.75 the oxygen coverage was reduced from 3 to $2 \mathrm{ML}$. The mechanism to reach these coverages could be described by the model of Holloway and Hudson [6], which is characterized by a temperature independent chemisorption followed by a nucleation process with additional lateral growth of these oxide nuclei.

The end of the chemisorption stage is characterized by a saturation in oxygen uptake. The length of this saturation period depends on the anneal temperature of the crystal prior to oxidation. Hanekamp et al. [23] have shown for a Ni(110) crystal that the length of this saturation period could be changed from 0 to $2 \mathrm{~L}$ by lowering the anneal temperature from 740 to $570 \mathrm{~K}$. The nucleation stage is inversely related to the sample temperature, thus increasing temperature leads to a decrease in nucleation rate. 
Table 2

Change in ellipsometric parameters $\Delta$ and $\psi$ due to oxidation as a function of initial oxygen concentration at the surface of Incoloy $800 \mathrm{H}$, after bombardment and relaxation at $T=300 \mathrm{~K}$, $P_{\mathrm{O}_{2}}=2.3 \times 10^{-5} \mathrm{~Pa}$

\begin{tabular}{lll}
\hline Initial oxygen concentration $(\mathrm{at} \%)$ & $\delta \Delta(\mathrm{deg})$ & $\delta \psi(\mathrm{deg})$ \\
\hline 2.0 & 2.32 & 0.03 \\
4.0 & 2.21 & 0.02 \\
6.0 & 2.19 & 0.03 \\
7.0 & 2.10 & 0.02 \\
\hline
\end{tabular}

The oxidation of stainless steels, however, shows a temperature independent part up to a $3 \mathrm{ML}$ coverage. The linearity between $\delta \Delta$ and $\delta \psi$ indicates that during this stage only a single process is involved [12]. Because the polarizability of chemisorbed oxygen is different from that of oxide, one would expect a change in the $\delta \Delta-\delta \psi$ curve, whenever the oxidation mechanism changes from chemisorption to oxide nucleation and lateral growth of oxide islands. After the $3 \mathrm{ML}$ coverage such a clear change in the $\delta \Delta-\delta \psi$ curve appears, indicating the onset of a new process. Another indication that the surface saturation of oxygen is important is the dependence of $\delta \Delta$ and $\delta \psi$ upon oxygen concentration in the surface layer. Table 2 shows that there is a direct relation between the cleanness of the surface and the ultimate change in $\Delta$ and $\psi$. The only difference between the oxidations listed in table 2 , is the initial change in the ellipsometric parameters. The subsequent oxidations, indicated by the change in $\delta \Delta-\delta \psi$ curves, agreed, in all cases, within experimental error. Hanekamp et al. [23] reported that no difference could be found, for $\mathrm{Ni}(110)$, between initial oxidations performed without oxygen or with 5 at\% oxygen present prior to oxidation. They explained this behaviour by suggesting that the 5 at\% oxygen present at the surface, was dissolved oxygen in the layer just below the $\mathrm{Ni}(110)$ surface. This dissolved oxygen did not take part in the oxidation process. However, it is clear (table 2) that this is not the case in the oxidation of stainless steel, explaining the differences in oxidation behaviour between $\mathrm{Ni}$ and stainless steel. If oxygen chemisorption would be the first step in the oxidation process, one would expect to find an enrichment of the surface in chromium, for the free enthalpy of the oxidation of chromium is more negative than that of iron. However, XPS data [24] show that iron and chromium are oxidized simultaneously and at the same rate. Only at high temperatures $(T>600 \mathrm{~K})$ is chromium oxidized preferentially.

The reported influence of $\mathrm{Ar}$ ion bombardment conditions [26] on the oxidation behaviour of Incoloy $800 \mathrm{H}$ suggests that the initial oxidation process is one of oxygen incorporation in the first surface layers: i.e., the initial oxidation behaviour was very much affected by the ion density of the bombardment. The number of defects created by the bombardment was 
linearly related to the initial change in $\delta \Delta$ and $\delta \psi$, suggesting oxygen incorporation in the amorphized layer.

There are some differences between the surface treatments of the stainless steels and that of nickel in the literature, which might explain some differences in the oxidation behaviour. The oxidations of $\mathrm{Ni}$ have all been performed on Ni single crystals, which were annealed prior to oxidation. The stainless steel surfaces used in this investigation were polycrystalline and had not been annealed. The specimens were always used in the amorphized state produced by the Ar-ion bombardment without subsequent annealing, because the main interest was the study of the influence of previously applied cold work on the initial oxidation behaviour. Another reason why the stainless steel surfaces were not given an anneal treatment was the surface segregation of chromium at temperatures above $600 \mathrm{~K}$ [1]. In conclusion it is suggested that the initial oxidation of stainless steel is characterized by oxygen incorporation up to a saturation of $3 \mathrm{ML}$.

\subsection{Subsequent oxidation}

The low temperature subsequent oxidation can be described by a logarithmic rate equation. The high temperature oxidations show parabolic behaviour. Fehlner and Mott (FM) [18] deduced a logarithmic rate equation for field-assisted ion movement. Eley and Wilkinson (EW) [16] introduced a term depending on the structure of the film. In this way recrystallization, reconstruction and grain boundary diffusion are taken into account. The activation energies are given by $E=W+\mu x$ [8] (EW), and $E=W+\mu x-\frac{1}{2} q a F$ [9] (FM). From a plot of the rate $\mathrm{d} \delta \Delta / \mathrm{d} t$ versus $\delta \Delta$, this structural term $\mu$ can be determined (fig. 7).

The overall activation energy of the subsequent oxidation experiment can be determined from the slope of the rate $\mathrm{d} \delta \Delta / \mathrm{d} t$ against $1 / T$, where the rate is taken at a constant $\delta \Delta\left(\sim 2.4^{\circ}\right)$ (fig. 8). In this way the structural term is known and $W-\frac{1}{2} q a F(\mathrm{FM})$ or $W(\mathrm{EW})$ can be calculated. The activation energy in the EW model became negative for some oxidation experiments, indicating that more processes are involved.

In the FM model the field is assumed to be constant as the oxide thickens, so that it can be calculated by estimating the potential difference at the onset of logarithmic oxide growth. The potential difference for a flat plate capacitor is given by

$$
V=Q d / 4 \pi \varepsilon A \text {, }
$$

where $Q$ is the total charge, $d$ the oxide thickness and $A$ the area of the condenser. $Q$ can be estimated from the number of available sites for oxygen adsorption on an oxide $\left(\sim 1.0 \times 10^{+18} \mathrm{~m}^{-2}\right)$. With $d=1.0 \mathrm{~nm}$ and $\omega \approx 5$ one obtains $\frac{1}{2} q a F \approx 150 \mathrm{~kJ} \mathrm{~mol}^{-1}$ and the activation energy becomes $\sim 100 \mathrm{~kJ}$ 


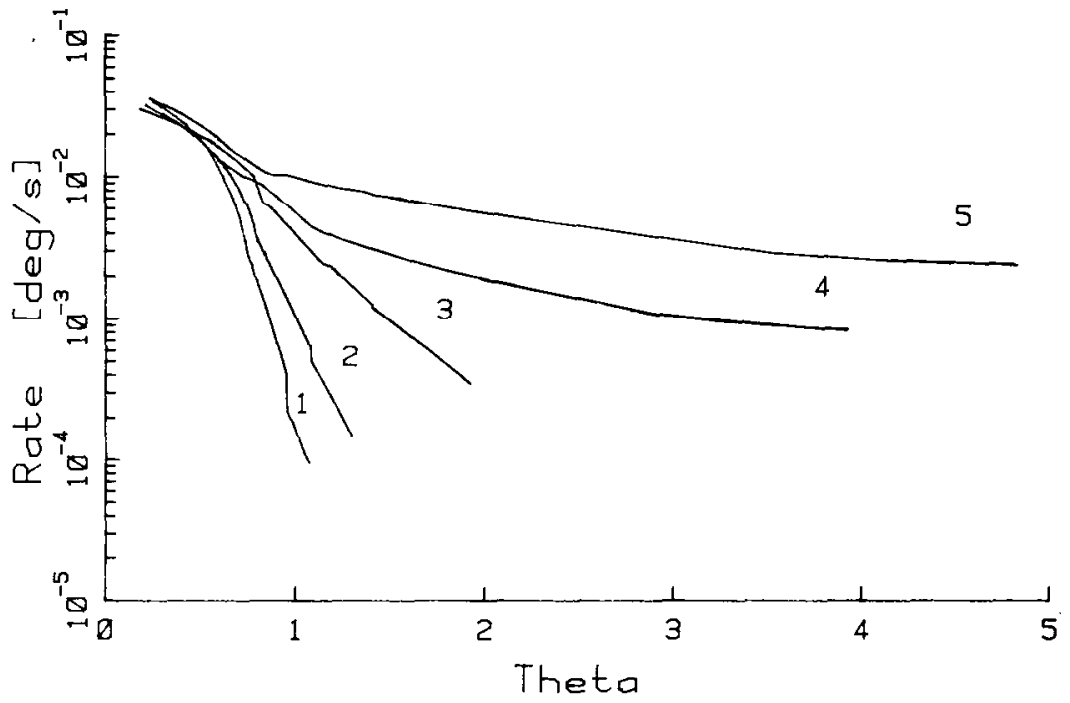

Fig. 7. Oxidation rate $\mathrm{d} \delta \Delta / \mathrm{d} t$ as a function of $\theta(=\delta \Delta / \Delta$ sat $)$. (Incoloy $800 \mathrm{H}$, undeformed.) Oxidation pressure $P_{\mathrm{O}_{2}}=2.5 \times 10^{-5} \mathrm{~Pa}$; temperatures: (1) $300 \mathrm{~K}$, (2) $375 \mathrm{~K}$, (3) $480 \mathrm{~K}$, (4) 570 $\mathrm{K}$, (5) $720 \mathrm{~K}$.

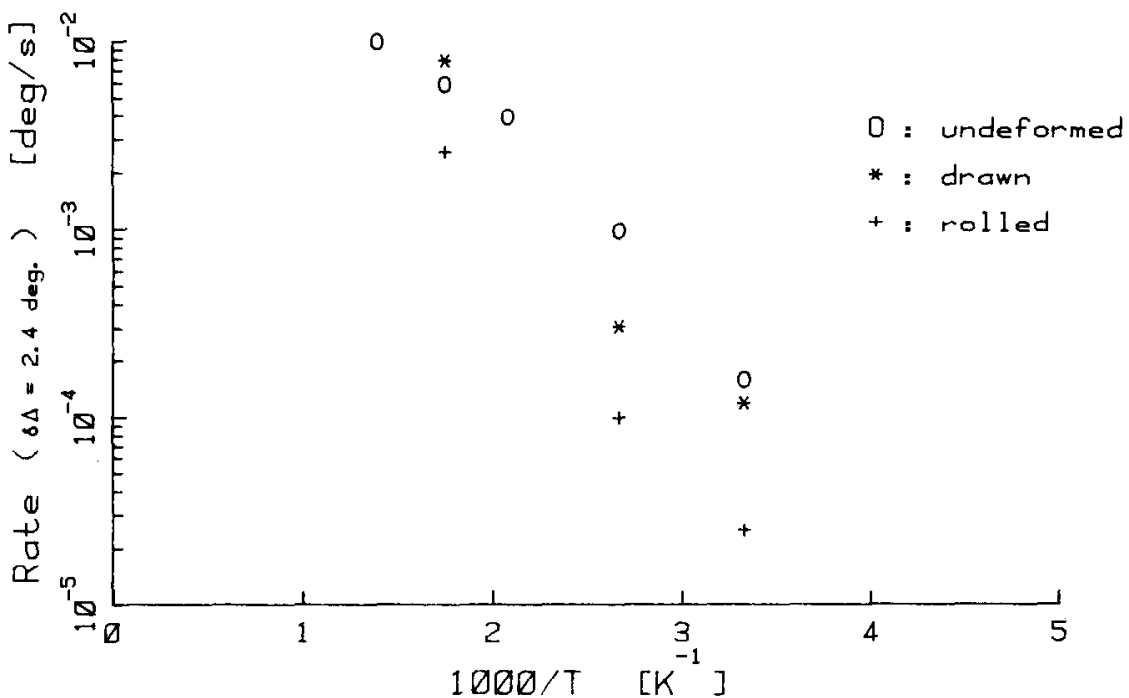

Fig. 8. Oxidation rate at constant oxide thickness as a function of $1 / T$. (Incoloy $800 \mathrm{H}$, undeformed.) 
Table 3

Activation energies for the LTO of stainless steel

\begin{tabular}{|c|c|c|c|c|}
\hline Material & Pretreatment & $\begin{array}{l}T \\
(\mathrm{~K})\end{array}$ & $\begin{array}{l}\mu \\
\left(\mathrm{kJ} \mathrm{mol}^{-1} \mathrm{~A}^{-1}\right)\end{array}$ & $\begin{array}{l}E \\
\left(\mathrm{~kJ} \mathrm{~mol}^{-1}\right)\end{array}$ \\
\hline \multirow[t]{9}{*}{ AISI 304} & Undeformed & 300 & 4.9 & \\
\hline & & 375 & 1.9 & 33 \\
\hline & & 480 & 0.6 & \\
\hline & Rolled $75 \%$ & 300 & 5.8 & \\
\hline & & 375 & 2.9 & 21 \\
\hline & & 480 & 7.8 & \\
\hline & Rolled $20 \%$ & 300 & 5.4 & \\
\hline & & 375 & 4.1 & 24 \\
\hline & & 480 & 1.1 & \\
\hline \multirow[t]{11}{*}{ Incoloy $800 \mathrm{H}$} & Undeformed & 300 & 18.0 & \\
\hline & & 375 & 18.0 & \\
\hline & & 480 & 13.0 & 22 \\
\hline & & 570 & 5.4 & \\
\hline & & 720 & 5.1 & \\
\hline & Rolled $75 \%$ & 300 & 16.6 & \\
\hline & & 375 & 8.4 & 21 \\
\hline & & 570 & 7.4 & \\
\hline & Drawn $20 \%$ & 300 & 21.0 & \\
\hline & & 375 & 18.0 & 28 \\
\hline & & 570 & 11.7 & \\
\hline
\end{tabular}

$\mathrm{mol}^{-1}$. This is reasonably close to the bond strength of oxides $\left(-80 \mathrm{~kJ} \mathrm{~mol}^{-1}\right.$ for $\mathrm{FeO}, \sim 100 \mathrm{~kJ} \mathrm{~mol}^{-1}$ for $\mathrm{NiO}$ and $\sim 200 \mathrm{~kJ} \mathrm{~mol}^{-1}$ for $\mathrm{Cr}_{2} \mathrm{O}_{3}$ [18]) and it suggests that bonds have to be broken in order to make diffusion possible so that cation diffusion occurs via lattice sites

In table 3 a survey of apparent activation energies is given for Incoloy $800 \mathrm{H}$ and AISI 304.

\section{Conclusions}

The initial oxidation behaviour of stainless steel is governed by a temperature independent incorporation of oxygen atoms in the first 3 layers of the metal surface. The subsequent oxidation only proceeds if the surface layer is saturated with oxygen. The mechanism by which the oxidation proceeds is a field-assisted cation movement. The electric field, built up as a consequence of electron transfer from the metal atoms to the oxygen, remains constant during 
the oxidation process. The apparent activation energy for the ion movement is about $100 \mathrm{~kJ} \mathrm{~mol}^{-1}$.

The surface condition plays an essential role in the observed kinetics of the formation of the first oxide layer. The subsequent oxidation is hardly influenced by it and the mechanism of oxidation is the same for all pretreatments.

\section{Acknowledgements}

The authors wish to thank A. van Silfhout, A. van der Voort, L. Lefferts and D. Heslinga for performing some of the experimental work and for all helpful discussions.

\section{References}

[1] J.C. Langevoort, A. van der Voort and L.J. Hanekamp, in: Proc. ICMC.9, Toronto, 1984, Vol. 2, p. 406.

[2] J.C. Langevoort, T. Fransen and P.J. Gellings, Oxidation Metals 21 (1984) 271.

[3] D. Caplan, M.J. Graham and M. Cohen, J. Electrochem. Soc. 119 (1972) 1205.

[4] M.J. Graham, G.I. Sproule, D. Caplan and M. Cohen, J. Electrochem. Soc. 119 (1972) 883.

[5] K. Ledjeff, A. Rahmel and M. Schorr, Oxidation Metals 15 (1981) 485.

[6] P.M. Holloway and J.B. Hudson, Surface Sci. 43 (1974) 123.

[7] P.M. Holloway and J.B. Hudson, Surface Sci. 43 (1974) 141.

[8] D.F. Mitchell, P.B. Sewell and M. Cohen, Surface Sci. 61 (1976) 355.

[9] C.R. Brundle, T.J. Chuang and K. Wandelt, Surface Sci. 68 (1977) 459.

[10] L.J. Hanekamp and A. van Silfhout, J. Phys. (Paris) 44 (1983) C10-469.

[11] P.H. Holloway, J. Vacuum. Sci. Technol. 18 (1981) 653.

[12] F. Meyer and G.A. Bootsma, Surface Sci. $16(1969) 221$.

[13] K.R. Lawless, Rept. Progr. Phys. 37 (1974) 231.

[14] N.F. Mott, Trans. Faraday Soc. 39 (1940) 472; 43 (1947) 429.

[15] N. Cabrera and N.F. Mott, Rept. Progr. Phys. 12 (1948-49) 143.

[16] D.D. Eley and P.R. Wilkinson, Proc. Roy. Soc. (London) A254 (1960) 327.

[17] R.W. Bartlett, J. Electrochem. Soc. 111 (1944) 903.

[18] F.P. Fehlner and N.F. Mott, Oxidation Metals 2 (1970) 59.

[19] L.J. Hanekamp, W. Lisowski and G.A. Bootsma, Surface Sci. 118 (1982) 1.

[20] P.R. Norton, R.L. Trapping and J.W. Goodale, Surface Sci. 45 (1977) 13.

[21] S. Pednekar and S. Smialowska, Corrosion 19 (1980) 565.

[22] J.C. Langevoort, T. Fransen and P.J. Gellings, Werkstoffe Korrosion 34 (1983) 500.

[23] L.J. Hanekamp, S.J.H. Brader and G.A. Bootsma, Surface Sci. 135 (1984) 386.

[24] J.C. Langevoort, I. Sutherland and P.J. Gellings, to be published.

[25] M. Seo and N. Sato, Oxidation Metals 19 (1983) 151.

[26] J.C. Langevoort, D.C. Heslinga, L.J. Hanekamp, A. van Silfhout, L. Lefferts and P.J. Gellings, in: Reactivity of Solids, Proc. ISRS-10, Dijon, Eds. P. Barret and L.-C. Dufour (Elsevier, Amsterdam, 1985) p. 209.

[27] G.J. Stokkers, A. van Silfhout, G.A. Bootsma, T. Fransen and P.J. Gellings, Corrosion Sci. 23 (1983) 185 . 